\title{
Significance of CC Group of Chemokines in Oral Squamous Cell Carcinoma and Oral Potential Malignant Disorders: A Review
}

\author{
Roopa Yadahalli ${ }^{1}$, Gargi S Sarode ${ }^{2}$, Sachin C Sarode ${ }^{3}$, Shankargauda Patil ${ }^{4}$
}

\begin{abstract}
Aim and objective: The underlying association of the $\mathrm{CC}$ group of cytokines and its systemic role in fibrosis.

Background: Chemokines the secretory proteins are produced by leukocytes and other tissue cells integrally or after induction, function regionally in a paracrine or autocrine manner.

Review results: Functionally chemokines are split into constitutive (homeostatic, housekeeping, or lymphoid) and inducible (inflammatory) ones presented by cells, based on the conditions of their production or can be both. Chemotactic proteins have a vital role in host defense activities by developing and maintaining innate and acquired immunity. Importantly, chemokines also participate in wound healing, angiogenesis/ angiostasis, lymphocyte polarization, apoptosis, fibrosis, and the development and metastasis of tumors.

Conclusion: It reviews the $\mathrm{CC}$ chemokine in health and physiology then the role of it in inflammation, immune diseases, oral potentially malignant disorders (OPMDs), and development and metastasis of the tumor.

Clinical significance: The diseases where inflammation and fibrosis play an important role continue to grow and therefore the need for safe and effective anti-fibrotic therapies is great and is also likely to increase.

Keywords: CC chemokines, Chemokines, Oral potentially malignant disorders, Oral squamous cell carcinoma.

World Journal of Dentistry (2021): 10.5005/jp-journals-10015-1804
\end{abstract}

\section{BACKGROUND}

Chemokines the secretory proteins are secreted by leukocytes and other cells integrally or on inducing. They apply their function regionally in a paracrine or autocrine manner. They are basically smaller in structure than cytokines which are usual for leukocyte chemoattractant with a lead role in the stimulation of leukocyte and chemotaxis. ${ }^{1}$ Chemokines are basically isolated into categories based on the $\mathrm{NH}_{2}$-terminal motif of two conserved cysteine residues: $C, C C, C X C$, and $C X^{3} C$. The signaling is by receptors of $G$ proteincoupled (GPCRs), labeled as XCR, CCR, CXCR, and CX3CR as per the nomenclature of chemokine. ${ }^{2}$ Functionally chemokines are split into constitutive and inducible or inflammatory types depending on the state of their production or can be both. ${ }^{1}$ Homeostatic chemokines are significant for numerous physiological events by regulating subsets of cells during embryogenesis by hematopoiesis, organogenesis, and cell proliferation. ${ }^{3}$ And presentation of inducible type is activated through inflammatory stimulus which is expressed by epithelial cells, endothelial cells, fibroblasts, and so on. These proteins have their role in host defense activities by developing and maintaining innate and acquired immunity. Importantly, chemokines aid in wound healing, angiogenesis/ angiostasis, lymphocyte polarization, apoptosis, fibrosis tumor development, and metastasis. ${ }^{4,5}$

Many of the chemokines are proved to be major profibrotic mediators, proinflammatory factors, and even angiogenic mediators which aiding in fibrosis in various organs and even major role in tumorigenesis. This review explores the CC chemokine in health and physiology than the role of it in inflammation and immune diseases. The purpose of this paper is to understand the pathophysiology of the CC group of chemokines in oral potentially
${ }^{1-3}$ Department of Oral Pathology and Microbiology, Dr. DY Patil Dental College and Hospital, Dr. DY Patil Vidyapeeth, Pune, Maharashtra, India ${ }^{4}$ Department of Maxillofacial Surgery and Diagnostic Sciences, Division of Oral Pathology, College of Dentistry, Jazan University, Jazan, Kingdom of Saudi Arabia

Corresponding Author: Roopa Yadahalli, Department of Oral Pathology and Microbiology, Dr. DY Patil Dental College and Hospital, Dr. DY Patil Vidyapeeth, Pune, Maharashtra, India, Phone: +91 9552560605, e-mail: roopa.madalli@gmail.com

How to cite this article: Yadahalli R, Sarode GS, Sarode SC, et al. Significance of CC Group of Chemokines in Oral Squamous Cell Carcinoma and Oral Potential Malignant Disorders: A Review. World J Dent 2021;12(2):160-165.

Source of support: Nil

Conflict of interest: None

malignant disorders (OPMDs) and the development and metastasis of the tumor. By understanding the role of these chemokines, the therapeutic intervention targeting them or its activators can be developed.

\section{Discussion}

\section{Chemokine}

$\mathrm{CC}$ chemokines belong to the b-family consist of two adjacent cysteines near the $\mathrm{N}$-terminus are commonly known as CCLs (CC Ligands). Twenty-seven members have been identified of this group and are numbered CCL-1 to CCL-28, as CCL-9 is the same as CCL-10. Mostly, chemokines in this family pertain to four cysteines 
(C4-CC chemokines) but some contain six (C6-CC chemokines). They stimulate the migration of monocytes, natural killer cells, and dendritic cells which share some receptors of CC chemokines. ${ }^{1,6}$ These secreted proteins traverse by the circulatory system, for activation of an extracellular component of their associated receptors belonging to distinctive cell variants. ${ }^{7}$

\section{Chemokine in Health and Physiology}

\section{Role of CC Chemokines in Embryonic Development}

Chemokines hold a major part during the development of the endometrium of the uterine before the embryo attachment. The chemokine-receptor functioning for maternal-fetal junction provides human embryo to migrate and move into endometrium pertaining to the epithelium. ${ }^{8}$ The expression of CX3CR1, CCR1, and CCR3 receptors along with their ligands are seen in the endometrial region of human trophoblasts. ${ }^{9}$ The trophoblast even stimulates CXCL1, CXCL2, and CCL8 expression of maternal decidualized stromal cells intervening the signal among them for facilitating fetus impregnation. ${ }^{10}$ The interactions for fetomaternal directing trophoblast migration along maternal endometria involvement of CCL14 and CCL4 are noted. $^{8}$

\section{Role of CC Chemokines in Immunity}

Almost in all cell types, chemokine-mediated cell migration has been pictured; although its physiological function is mostly involved in chemokine stimulation with the recruitment of immune cells. ${ }^{10}$ In both types of immunity, CC chemokines exhibit a crucial role. The CCL19 and CCL21 chemokines prompt CCR7 receptor existing on innate immune cells native $T$ and $B$ cells, mature DC/ Langerhans cells (LC), and CD56 bright $N K$ cells and trigger the movement to $T$ cell region of secondary immune organs. ${ }^{11}$ The ligands of immature dendritic cells explicit CXC receptor 1, CC receptor 1, 2, and 6 for inflammatory chemokines which directs them to the site of inflammation. ${ }^{11}$

The movement of $\mathrm{T}$ cells to tissues of secondary lymphoid is moderated by CCL21 which is exhibited profoundly in endothelial cells of lymph node venules. ${ }^{12}$ By contradiction, while pathogenic inflammation, like in infection, trauma, or malignancy, channelization of a different array of chemokines can be seen. The channelization of such a set of chemokines mainly is controlled by their formation in the regional site of inflammation. ${ }^{13}$ The large range of chemokines is initiated by inducible types as tumor necrosis factor and interferon- $\gamma .{ }^{5}$ Then, the immune components activated are attracted by these chemokines. ${ }^{14}$ Mostly, chemokines govern the placement of immune cells via circulation and also in tissue, inclusive of environment-specified stroma and extracellular matrices. In numerous disorders related to autoimmunity and inflammation, like colitis and dermatitis, uncontrolled presentation of numerous chemokines is seen. ${ }^{6}$

\section{Chemokines in Wound Healing and Angiogenesis}

In the process of appropriate healing of a wound, chemokines have a vital role. The expression of CCL27 speeds up the healing of a wound by the implementation of precursor cells of bone marrow-derived keratinocytes. ${ }^{15}$ The initiation of CCR2 present on endothelial cells leads to the expression of CCL2 further mediating neovascularization and also of vascular endothelial growth factor A (VEGF-A) and monocyte chemoattractant protein-1 (MCP-1). ${ }^{16}$ The CCL2, CCL11, and CCL16 have a part in regulating angiogenesis. ${ }^{17}$ Even the role of these small proteins which either initiate or suppress angiogenesis mediated by chemokines is an important point for healing wounds and inhibiting tumor growth, respectively.

\section{Chemokine Pathophysiology}

\section{Chemokine in Autoimmune Diseases}

The diseases related to autoimmunity are interpreted as a condition with ungoverned inflammation and increased infiltration of immune cells in the connective tissue. Increased expression of various chemokines in disorders as Crohn's or ulcerative colitis is seen, which was directly related to mucosal lymphocyte and leukocyte infiltration. ${ }^{18,19}$ Same kind of results is seen in inflammatory dermatological disorders, with the expression of numerous chemokines which are believed to control the chemotaxis of many dermal penetrating effector cells. ${ }^{20-22}$ In psoriasis and atopic dermatitis, excursive placement of T cells is performed by a wide variety of chemokines. Correlation of the elevated presentation of certain chemokines with a high invasion of immune cells in lesions and plaques of type 2 diabetes, multiple sclerosis, and atherosclerosis is shown. ${ }^{23,24}$

\section{Chemokine in Oral Potentially Malignant Disorders}

Oral squamous cell carcinoma (OSCC) sixth-most prevailing malignancy globally, occurs via a stepwise model accumulated by genetic abnormalities. They also result from lesions related to OPMDs, which have a high possibility of malignant transformation (MT) than the histologically normal oral mucosa. ${ }^{25}$

Oral lichen planus (OLP) is an OPMD with features of chronic inflammation of the oral mucosal membrane showing immune destruction in basal epithelial cells. The pivotal part is played by chemokines by incorporating $T$ cell selectively by their receptors liberated by affected epithelial cells, and the related inflammatory infiltrate. ${ }^{26}$ The receptors CXCR3 and CCR5 express type $1 \mathrm{~T}$ cells expression, whereas CCR3, CCR4, and CCR8 express type $2 \mathrm{~T}$ cells. Type 1 and 2 cells are differentiated by their secretion of cytokines. ${ }^{26,27}$ In OLP, the expression of RANTES/CCL5, CCL20 and CCR1, CCR6 have been noted in lesional keratinocyte cells. ${ }^{28,29}$ Even the chemokine CCL18 and 19 were seen elevated in OLP. The lamina propria of OLP presented RNA particular to receptors CXCR3 and CCR5, by this the infiltration of T cells seems to be controlled via these receptors. ${ }^{30} \mathrm{C}-\mathrm{CCL} 5$ and CCL17 and its receptor CCR5 and CCR4, respectively, were found to have a major part in activating and recruitment of T cells in OLP. ${ }^{31,32}$

The CCL2 positivity in basal cells and fibroblasts in oral submucous fibrosis (OSMF) showing a positive correlation with smooth muscle actin (a-SMA) was reported. The study also revealed the increased expression of CCL2 in advanced OSMF stages in comparison to early OSMF. This suggested that fibroblast might have an active part regarding CCL2 secretion associated with OSMF, which has a role in recruiting myofibroblasts at the site of disease. This shows that there could be a key linkage of the CCL2related recruitment of myofibroblasts pathway in the pathogenesis of OSMF. ${ }^{4}$ Table 1 shows the studies related to the CCL group of chemokines in OPMDs.

The etiopathogenesis of OLP related to chemokines studied till now is by the recruitment of T-lymphocytes through chemokine receptors. And in OSMF, the CCL2-related recruitment of the myofibroblasts pathway in fibrosis has been noted in pathogenesis.

\section{Chemokine in Cancer}

The progression of the tumor is strongly affected by the generation of chemokines by tumor and stromal cells. Leukocytes and tumor 
CC Group of Chemokines in OSCC and OPMDs

Table 1: Chemokine/chemokine receptor expression in oral potential malignant disorders studies

\begin{tabular}{|c|c|c|c|c|c|}
\hline Lesion & Chemokine & Receptor(s) & Sample type & Main findings(s) & Ref. \\
\hline \multirow[t]{5}{*}{ OLP } & $\begin{array}{l}\text { RANTES/CCL5, CCL18, } \\
\text { CCL19, CCL20, CCL17 }\end{array}$ & CCR1, CCR5 & Formalin fixed tissues & $\uparrow$ CCL5 in oral squamous cells & 28 \\
\hline & & & Peripheral blood and tissue & $\uparrow C C L 5 \uparrow$ mast cell trafficking & 29 \\
\hline & & & & $\begin{array}{l}\uparrow \text { CCL5 advocates proliferation and } \\
\text { migration of T-cell and inhibition of } \\
\text { T-cell apoptosis }\end{array}$ & 31 \\
\hline & & CCR6 & Tissue & $\begin{array}{l}\uparrow \text { CCL18, CCL19, CCL20 } \uparrow \text { Langerhans } \\
\text { cells and T-cell infiltration }\end{array}$ & 30 \\
\hline & & CCR4 & Peripheral blood & $\begin{array}{l}\uparrow \text { CCL17 inflammatory infiltration of } \\
\text { T cells }\end{array}$ & 32 \\
\hline OSMF & CCL2 & & Formalin-fixed tissues & $\uparrow C C L 2 \uparrow$ oral submucous fibrosis & 4 \\
\hline
\end{tabular}

cells are directionalized by chemokines and their receptors for moving and metastasis, access to the circulation, homing, and dissemination to definite tissues. Increased demonstration of chemokines and their receptors causing abnormal signaling and expression has been noted in many malignancies. ${ }^{33}$ Table 2 enlists the studies related to the CCL group of chemokines in OSCC.

Numerous studies till now noted the importance of CCL2 in various cancer types ${ }^{33,34}$ and notable preclinical antitumor action was clarified by blocking it. Many have revealed the presence of CCL2 in OSCC and HNSCC. ${ }^{33,35}$ An increased level of it is seen in OSCC and HNSCC with nodal metastasis and tumor invasion. ${ }^{33,35}$ Oral carcinoma-associated fibroblasts (CAFs) which were arbitrated by CCL2 has been observed about the functional affirmation of proliferation, invasion, and tumor growth in OSCC was demonstrated. ${ }^{36}$ Higher risk of development of OSCC was explained in a study were gene polymorphism of CCL2 and CCR2 on the patients. This showed allelism of $\mathrm{G}$ and GG genotype for CCL2 and allelism of 641 and wt/64I genotype for CCR2 has markedly on the higher side with risk for OSCC. Looking at their results, the polymorphism mechanisms which resulted in aggravation of transcription of chemokine and finally, augmentation of its role was proposed. ${ }^{35}$

The chemokines CCL3 and CCL5 were expressed high with various malignancies. In oral malignancy and even metastatic lymph nodes, CCL3 expression along with its receptor CCR1 is observed. ${ }^{37,38}$ Chuang et al. have observed the presence of CCL5 in cell lines of OSCC. ${ }^{39}$ Provocation by CCL5 initiated movement and induction of matrix metalloproteinase-9 (MMP-9). A positive association was observed in CCR5 gene types and its genotypes with more chance in OSCC occurrence. ${ }^{40}$ To rectify CC chemokine receptor CCR5 which was found dysregulated in a study, treated with interferon-a2b (IFN-a2b), showed downregulation of CCR5. ${ }^{41}$ Few investigations revealed the therapeutic advantage of immunotherapy by enhancing T-cell-mediated tumor suppression by IFN-a2b treatment. ${ }^{42}$

The CCL7-mediated cytoskeleton modifications were noted in cells of oral malignancy which had the property of enhancing tumor invasion and migration. ${ }^{43}$ The correlation compelled with CCL19/CCL21/CCR7 appearance, showed nodal metastasis and bad prognostication of OSCC in few studies. ${ }^{44-46}$ The CCL21/CCR7 initiates cytoskeleton modifications leading to migrating, invading, adhesion, and cell survival of tumor cells by activating PI3K/AKT and MAPK's pathway with the release of MMP-9. ${ }^{47-50}$ CCL18 was upregulated in the OSCC patients in an advanced stage with metastasis of cervical lymph node than those with early clinical stage and without cervical lymph node metastasis. ${ }^{51}$ The CCL20 expression was first demonstrated in OSCC tissue and six types of OSCC cell lines by Abiko et al. ${ }^{52}$ According to their observation, CCL20 upregulation was expressed upon stimulus by bacteria or inflammation in cultured cells of OSCC. ${ }^{52}$ In a study conducted, the involvement of CCL20 expression in metastatic nodes with a poor prognosis was seen. Even they noted that suppressing the chemokine CCL20 by interfering with RNA's, decreased migration and invasion. ${ }^{53}$

The study conducted by Wang et al. revealed CCL18 increased the migration of cells causing invasion with the epithelialmesenchymal transition (EMT). The feature of cancer stem (like) cells is induced by CCL18 in oral cancer cells. Immunohistochemical study on surgical tissue of OSCC showed a positive association with the presence of CCL18 and Bmi-1. The cells treated by CCL18 showed increased association with significantly high results in octamerbinding transcription factor 4 and Bmi-1, and bulks of aldehyde dehydrogenase positive and $\mathrm{CD}_{133^{+}}$cells when compared with untreated cells. Moreover, Slug expression was upregulated by CCL18 by stimulation of the signaling pathway mTOR in cell line study of OSCC. The reversal of EMT induced by CCL18 and the stem cell-like character at molecular and even in functional levels was seen on blocking of this pathway by INK128, or knockdown of Slug by RNA hindrance. ${ }^{54}$

Lien et al. showed in a study that was in vitro and in vivo related to oral cancer cells about CCL4 which increased VEGF-C presentation leading to lymphangiogenesis. In favor of it miR195-3p mimic counteracted CCL4-mediated expression of VEGF-C. In oral malignant cells, the activation of CCL4 intensified JAK2 and STAT3 phosphorylation. ${ }^{55}$ CCL18 is a novel marker for the OSCC malignancy and prognosis, including lymph node metastasis, timeto-recurrence, and disease-free survival time. ${ }^{55}$ Mao et al. suggested CCL18 is commonly expressed in OSCC tissue and expression status corresponded with tumor differentiation, metastasis, and prognosis. ${ }^{56}$ CCL18 was found in the OSCC progression by binding the CCL18-NIR1 axis which might initiate a signaling pathway related to JAK2/STAT3. This axis has seen to manage the proliferative, metastatic, and EMT of oral tumor cells by the JAK2/ STAT3 signaling pathway. ${ }^{57}$

The various chemokines and receptors of them are demonstrated by tumors, keratinocytes of OLP, and fibroblasts in OSMF. These expressed chemokines and chemokine receptors can be represented as an ideal target for immunotherapy. The chemokine receptor inhibitors can show promising results when given as combined therapy along with chemotherapeutic drugs or in antibody therapy against immune checkpoints. In the future, the inhibitors of chemokine receptors and chemokines can be used to 
Table 2: Chemokine/chemokine receptor expression in oral squamous cell carcinoma studies

\begin{tabular}{|c|c|c|c|c|}
\hline Chemokine & Receptor(s) & Sample type in OSCC & Main findings(s) & Ref. \\
\hline \multirow[t]{3}{*}{ CCL2 } & \multirow[t]{3}{*}{ CCR2 } & \multirow[t]{3}{*}{ Cell line and xenografts tissue } & $\begin{array}{l}\uparrow C C L 2 \text { increase ROS and cell proliferation, } \\
\text { invasion, and tumor growth }\end{array}$ & \multirow[t]{3}{*}{$36-38$} \\
\hline & & & $\uparrow \mathrm{CCL} 2 \uparrow$ lymph node metastasis & \\
\hline & & & $\begin{array}{l}C C L 2 \text { and } C C R 2 \text { gene polymorphism } \uparrow \text { the risk } \\
\text { for OSCC }\end{array}$ & \\
\hline CCL3 & CCR1 & Cell lines & CCL3 $\uparrow$ nodal metastasis & 39 \\
\hline CCL4 & & Patient serum and tissue & $\uparrow C C L 4 \uparrow$ VEGF-C $\uparrow$ lymphangiogenesis & 55 \\
\hline \multirow[t]{3}{*}{ CCL5 } & \multirow[t]{3}{*}{$\begin{array}{l}\text { CCR1, CCR3, } \\
\text { CCR5 }\end{array}$} & \multirow[t]{3}{*}{ Cell line peripheral blood samples } & $\begin{array}{l}\uparrow \mathrm{CCL} 5 \uparrow \text { motility } \uparrow \text { migration of cells with } \uparrow \\
\text { MMP-9 }\end{array}$ & \multirow[t]{3}{*}{$40-42$} \\
\hline & & & $\uparrow \mathrm{CCL} 5 \uparrow$ CCR5 increased OSCC & \\
\hline & & & CCL5-28 and CCL5-403 genes increased OSCC & \\
\hline CCL7 & $\begin{array}{l}\text { CCR1, CCR2, } \\
\text { CCR3, CCR5 }\end{array}$ & Tissue and cell line & CCR1/CCR3 hindrance causing cell invasion & 43 \\
\hline \multirow[t]{6}{*}{$\begin{array}{l}\text { CCL19/ } \\
\text { CCL21 }\end{array}$} & \multirow[t]{6}{*}{ CCR7 } & Tissue and cell line tissue & $\begin{array}{l}\uparrow C C R 7 \text { and } C C L 21 / C C R 7 \text { leading to nodal } \\
\text { metastasis. Advancement and increased tumor } \\
\text { size with invasion and adhesion to nodes }\end{array}$ & \multirow[t]{6}{*}{$44-50$} \\
\hline & & HNSCC & $\begin{array}{l}\uparrow \text { CCR7 causes increased node metastasis, } \\
\text { tumor size, clinical staging, local recurrence, } \\
\text { and adhesive ability }\end{array}$ & \\
\hline & & \multirow[t]{4}{*}{ HNSCC cell lines } & $\begin{array}{l}\uparrow C C R 7 \text { causes increased node metastasis, } \\
\text { migration, adhesion, and cytoskeletal reor- } \\
\text { ganization }\end{array}$ & \\
\hline & & & $\begin{array}{l}\uparrow \text { CCR7/CCL19 leading to increase in PI3K, } \\
\text { CDC42, and polymerization of actin }\end{array}$ & \\
\hline & & & $\begin{array}{l}\uparrow \text { CCR7 causing increased migration, MMP-9, } \\
\text { b1 integrin, and cytoskeletal reorganization }\end{array}$ & \\
\hline & & & $\begin{array}{l}\uparrow \text { CCR7/CCL19 with increases in ERK/JNK; E- } \\
\text { cadherin, vimentin, and tumor invasion }\end{array}$ & \\
\hline \multirow[t]{3}{*}{ CCL18 } & & \multirow{3}{*}{$\begin{array}{l}\text { Patient serum and tissue cell lines, HSC6, SCC15, } \\
\text { CAL33, and tumor tissue OSCC cell lines, patient } \\
\text { serum and tissue }\end{array}$} & $\uparrow$ Slug expression $\uparrow$ (mTOR) signaling pathway & 51 \\
\hline & & & $\begin{array}{l}\uparrow \text { Malignancy and prognosis, including lymph } \\
\text { node metastasis, time-to-recurrence, and } \\
\text { disease-free survival time }\end{array}$ & 54 \\
\hline & & & $\begin{array}{l}\uparrow C C L 18-N I R 1 \text { axis regulates proliferation, me- } \\
\text { tastasis, and EMT of OSCC cells through JAK2/ } \\
\text { STAT3 signaling pathway }\end{array}$ & 56,57 \\
\hline \multirow[t]{2}{*}{ CCL20 } & & \multirow[t]{2}{*}{ OSCC cell lines and tissue } & $\begin{array}{l}\uparrow \text { CCL20 increased nodal metastasis CCL20 } \\
\text { blocking showed cell invasion }\end{array}$ & \multirow[t]{2}{*}{$\begin{array}{l}43,53, \\
52\end{array}$} \\
\hline & & & $\begin{array}{l}\uparrow C C L 20 \text { activation by lipopolysaccharide and } \\
\text { TNF-a caused oral immunoresponse to bacte- } \\
\text { rial infection, which in turn involves tumor } \\
\text { growth }\end{array}$ & \\
\hline
\end{tabular}

regulate the tumor, to subdue chemotherapeutic drug resistance and the optimization of subjects regarding immune response can be done.

\section{Conclusion}

Chemokines have predominated in physiology and homeostasis along with tumor pathogenesis and metastasis. It reviews in short about the information that is considered needful regarding recognizing the function of chemokines in human pathophysiology. If we can reduce the burden of chronic inflammation, it will have a huge, positive effect on therapy. Therapeutic intervention targeting cytokines or its activators for cytokine-related disease management can prevent disease initiation and progression. The pattern of cytokines expression and quantitative clinical endpoints such as complete cytokine profiling to exactly know the rate progression of the disease is needed desperately. The burden of disease where inflammation, fibrosis, and tumor progression as major factors continues to grow, so the need for safe and effective anti-fibrotic and immunotherapies is of great value.

\section{References}

1. Baggiolini M. Chemokines in pathology and medicine. J Intern Med 2001;250(2):91-104. DOI: 10.1046/j.1365-2796.2001.00867.x. 
2. Bachelerie F, Ben-Baruch A, Burkhardt AM, et al. International Union of Basic and Clinical Pharmacology. Update on the extended family of chemokine receptors and introducing a new nomenclature for atypical chemokine receptors. Pharmacol Rev 2014;66(1):1-79. DOI: 10.1124/pr.113.007724.

3. Raman D, Sobolik-Delmaire T, Richmond A. Chemokines in health and disease. Exp Cell Res 2011;317(5):575-589. DOI: 10.1016/j. yexcr.2011.01.005.

4. Sarode G, Sarode S, Deshmukh R, et al. Myofibroblasts could be recruited in a chemokine ( $\mathrm{C}-\mathrm{C}$ motif) ligand 2-dependent manner in pathogenesis of oral submucous fibrosis. J Oral Path and Med 2017;46(6):443-447.

5. Murakami T, Cardones AR, Hwang ST. Chemokine receptors and melanoma metastasis. J Dermatol Sci 2004;36(2):71-78. DOI: 10.1016/j. jdermsci.2004.03.002.

6. Laing KJ, Secombes CJ. "Chemokines". Dev Comp Immunol 2004;28(5):443-460. DOI: 10.1016/j.dci.2003.09.006.

7. Roy I, Evans DB, Dwinell MB. Chemokines and chemokine receptors: update on utility and challenges for the clinician. Surgery 2014;155(6):961-973. DOI: 10.1016/j.surg.2014.02.006.

8. Hannan NJ, Jones RL, White CA, et al. The chemokines, CX3CL1, CCL14, and CCL4, promote human trophoblast migration at the fetomaternal interface. Biol Reprod 2006;74(5):896-904. DOI: 10.1095/ biolreprod.105.045518.

9. Hess AP, Hamilton AE, Talbi S, et al. Decidual stromal cell response to paracrine signals from the trophoblast: amplification of immune and angiogenic modulators. Biol Reprod 2007;76(1):102-117. DOI: 10.1095/ biolreprod.106.054791.

10. Rollins BJ. Chemokines. J Blood 1997;90(3):909-928. DOI: 10.1182/ blood.V90.3.909.

11. Esche C, Stellato C, Beck LA. Chemokines: key players in innate and adaptive immunity. J Invest Dermatol 2005;125(4):615-628. DOI: 10.1111/j.0022-202X.2005.23841.x.

12. Cyster JG. Chemokines and cell migration in secondary lymphoid organs. Science 1999;286(5447):2098-2102. DOI: 10.1126/ science.286.5447.2098.

13. Ogawa N, Ping L, Zhenjun $L$, et al. Involvement of the interferongamma-induced $T$ cell-attracting chemokines, interferon-gammainducible 10-kd protein (CXCL10) and monokine induced by interferon-gamma (CXCL9), in the salivary gland lesions of patients with Sjögren's syndrome. Arthritis Rheum 2002;46(10):2730-2741. DOI: 10.1002/art.10577.

14. Vecchi A, Massimiliano L, Ramponi S, et al. Differential responsiveness to constitutive vs. inducible chemokines of immature and mature mouse dendritic cells. J Leukoc Biol 1999;66(3):489-494.DOI: 10.1002/ jlb.66.3.489.

15. Inokuma D, Abe R, Fujita $Y$, et al. CTACK/CCL27 accelerates skin regeneration via accumulation of bone marrow derived keratinocytes. Stem Cells 2006;24:2810-2816.

16. Keeley EC, Mehrad B, Strieter RM. Chemokines as mediators of neovascularization. Arterioscler Thromb Vasc Biol 2008;28(11):19281936. DOI: 10.1161/ATVBAHA.108.162925.

17. Strasly M, Doronzo G, Capello P, et al. CCL16 activates an angiogenic program in vascular endothelial cells. Blood 2004;103(1):40-49. DOI: 10.1182/blood-2003-05-1387.

18. Kawashima D, Oshitani $N$, Jinno $Y$, et al. Augmented expression of secondary lymphoid tissue chemokine and EBI1 ligand chemokine in Crohn's disease. J Clin Pathol 2005;58(10):1057-1063. DOI: 10.1136/ jcp.2004.024828.

19. Ogawa $\mathrm{H}$, limura $M$, Eckmann $L$, et al. Regulated production of the chemokine CCL28 in human colon epithelium. Am J Physiol 2004;287(5):1062-1069. DOI: 10.1152/ajpgi.00162.2004.

20. Mabuchi T, Singh TP, Takekoshi T, et al. CCR6 is required for epidermal trafficking of gammadelta-T cells in an IL-23-induced model of psoriasi-form dermatitis. J Invest Dermatol 2013;133(1):164-171. DOI: 10.1038/jid.2012.260

21. Rottman JB, Smith TL, Ganley KG, et al. Potential role of the chemokine receptors $C X C R 3, C C R 4$, and the integrin alphaEbeta7 in the pathogenesis of psoriasis vulgaris. Lab Invest 2001;81(3):335-347. DOI: 10.1038/labinvest.3780242.

22. Homey B, Dieu-Nosjean MC, Wiesenborn A, et al. Up-regulation of macrophage inflammatory protein-3a/CCL20 and CC chemokine receptor 6 in psoriasis. J Immunol 2000;164(12):6621-6632. DOI: 10.4049/jimmunol.164.12.6621.

23. Mahad DJ, Trebst C, Kivisäkk P, et al. Expression of chemokine receptors CCR 1 and CCR5 reflects differential activation of mononuclear phagocytes in pattern II and pattern III multiple sclerosis lesions. J Neuropathol Exp Neurol 2004;63(3):262-273. DOI: 10.1093/jnen/63.3.262.

24. Cardona S, Garcia J, Cardona A. The fine balance of chemokines during disease: trafficking, inflammation, and homeostasis. Methods Mol Biol 2013;1013:1-16.

25. Jemal A, Bray F, Center MM, et al. Global cancer statistics. CA Cancer J Clin 2011;61(2):69-90. DOI: 10.3322/caac.20107.

26. Qin S, Rottman JB, Myers $\mathrm{P}$, et al. The chemokine receptors CXCR3 and CCR5 mark subsets of T cells associated with certain inflammatory reactions. J Clin Invest 1998:101(4):746-754. DOI: 10.1172/JCI1422.

27. Loetscher $P$, Uguccioni M, Bordoli L, et al. CCR5 is characteristic of Th1 lymphocytes. Nature 1998;391(6665):344-345. DOI: 10.1038/34814.

28. Little MC, Griffiths $C E$, Watson RE, et al. Oral mucosal keratinocytes express RANTES and ICAM-1, but not interleukin-8, in oral lichen planus and oral lichenoid reactions induced by amalgam fillings. Clin Exp Dermatol 2003;28(1):64-69. DOI: 10.1046/j.13652230.2003.01158.x.

29. Zhao ZZ, Sugerman PB, Walsh LJ, et al. Expression of RANTES and CCR1 in oral lichen planus and association with mast cell migration. J Oral Pathol Med 2002;31(3):158-162. DOI: 10.1034/j.16000714.2002.310306.x.

30. Ichimura M, Hiratsuka K, Ogura N, et al. Expression profile of chemokines and chemokine receptors in epithelial cell layers of oral lichen planus. J Oral Pathol Med 2006;35(3):167-174. DOI: 10.1111/j.1600-0714.2006.00402.x.

31. Shan J, Shan Li, Wang C, et al. Expression and biological functions of the CCL 5-CCR 5 axis in oral lichen planus. Exp Dermat 2019;28(7):816821. DOI: $10.1111 /$ exd.13946.

32. Shan J, Shen C, Fang J, et al. Potential roles of the CCL 17-CCR 4 axis in immuno-pathogenesis of oral lichen planus. J Oral Pathol Med 2019;00:1-7.

33. Sandhu SK, Papadopoulos K, Fong PC, et al. A first-in-human, firstin-class, phase I study of carlumab (CNTO 888), a human monoclonal antibody against CC-chemokine ligand 2 in patients with solid tumors. Canc Chemother Pharmaco 2013;71(4):1041-1050. DOI: 10.1007/s00280-013-2099-8.

34. Pienta KJ, Machiels JP, Schrijvers D, et al. Phase 2 study of carlumab (CNTO 888), a human monoclonal antibody against CC-chemokine ligand 2 (CCL2), in metastatic castration-resistant prostate cancer. Invest New Drugs 2013;31(3):760-768. DOI: 10.1007/s10637-012-98698.

35. Ferreira FO, Ribeiro FLL, Batista AC, et al. Association of CCL2 with lymph node metastasis and macrophage infiltration in oral cavity and lip squamous cell carcinoma. Tumour Biol 2008;29(2):114-121. DOI: 10.1159/000137669.

36. Li X, Xu Q, Wu Y, et al. A CCL2/ROS autoregulation loop is critical for cancer-associated fibroblasts-enhanced tumor growth of oral squamous cell carcinoma. Carcinogenesis 2014;35(6):1362-1370. DOI: 10.1093/carcin/bgu046.

37. Bektas-Kayhan K, Unur M, Boy-Metin Z, et al. MCP-1 and CCR2 gene variants in oral squamous cell carcinoma. Oral Dis 2012;18(1):55-59. DOI: 10.1111/j.1601-0825.2011.01843.x.

38. Silva TA, Unur M, Boy-Metin Z, et al. Dual role of CCL3/CCR1 in oral squamous cell carcinoma: implications in tumor metastasis and local host defense. Oncol Rep 2007;18:1107-1113.

39. Chuang JY, Yang WH, Chen HT, et al. CCL5/CCR5 axis promotes the motility of human oral cancer cells. J Cell Physiol 2009;220(2):418-426. DOI: $10.1002 /$ jcp. 21783. 
40. Tanyel CR, Cincin ZB, Gokcen-Rohlig B, et al. Effects of genetic variants of CCR5 chemokine receptors on oral squamous cell carcinoma. Genet Mol Res 2013;12(4):5714-5720. DOI: 10.4238/2013. November.18.20.

41. Weng CJ, Chien MH, Lin CW, et al. Effect of CC chemokine ligand 5 and CC chemokine receptor 5 genes polymorphisms on the risk and clinicopathological development of oral cancer. Oral Oncol 2010;46(10):767-772. DOI: 10.1016/j.oraloncology.2010.07.011.

42. Chakraborty K, Bose A, Goswami KK, et al. Dysregulated CC receptor/ ligand in monocytes/macrophages from tongue squamous cell carcinoma patients is partially rectified by interferon $\alpha-2 \mathrm{~b}$. Hum Immunol 2012;73(1):38-47. DOI: 10.1016/j.humimm.2011.10.015.

43. Jung DW, Che ZM, Kim J, et al. Tumor-stromal crosstalk in invasion of oral squamous cell carcinoma: a pivotal role of CCL7. Int J Cancer 2010;127:332-344.

44. Shang ZJ, Liu K, Shao Z. Expression of chemokine receptor CCR7 is associated with cervical lymph node metastasis of oral squamous cell carcinoma. Oral Oncol 2009;45(6):480-485. DOI: 10.1016/j. oraloncology.2008.06.005.

45. Tsuzuki H, Takahashi N, Kojima A, et al. Oral and oropharyngeal squamous cell carcinomas expressing CCR7 have poor prognoses. Auris Nasus Larynx 2006;33(1):37-42. DOI: 10.1016/j.anl.2005.07.019.

46. Irino $\mathrm{T}$, Takeuchi $\mathrm{H}$, Matsuda S, et al. CC Chemokine receptor CCR7: a key molecule for lymph node metastasis in esophageal squamous cell carcinoma. BMC Canc 2014;14(1):291. DOI: 10.1186/1471-2407-14-291.

47. Li P, Zhao ZJ, Liu FY, et al. The chemokine receptor 7 regulates cell adhesion and migration via beta1 integrin in metastatic squamous cell carcinoma of the head and neck. Oncol Rep 2010;24:989-995.

48. Zhao ZJ, Liu FY, Li P, et al. CCL19-induced chemokine receptor 7 activates the phosphoinositide- 3 kinase-mediated invasive pathway through Cdc42 in metastatic squamous cell carcinoma of the head and neck. Oncol Rep 2011;25:729-737.

49. Guo N, Liu F, Yang L, et al. Chemokine receptor 7 enhances cell chemotaxis and migration of metastatic squamous cell carcinoma of head and neck through activation of matrix metalloproteinase-9. Oncol Rep 2014;32(2):794-800. DOI: 10.3892/or.2014.3242.

50. Liu FY, Safdar J, Li ZN, et al. CCR7 regulates cell migration and invasion through MAPKs in metastatic squamous cell carcinoma of head and neck. Int J Onco 2014;45(6):2502-2510. DOI: 10.3892/ijo.2014.2674.

51. Jiang C, Yang D, Wang J. Correlations of abnormally upregulated CC chemokine ligand 18 (CCL18) with clinical stage and cervical lymph node metastasis status in serum and tumor tissue of patients with oral squamous cell carcinoma. Int J Clin Exp Pathol 2016;9(6):63176325.

52. Abiko Y, Nishimura M, Kusano K, et al. Expression of MIP-3alpha/ CCL20, a macrophage inflammatory protein in oral squamous cell carcinoma. Arch Oral Biol 2003;48(2):171-175. DOI: 10.1016/S00039969(02)00167-X.

53. Chang KP, Kao HK, Yen TC, et al. Overexpression of macrophage inflammatory protein-3a in oral cavity squamous cell carcinoma $\mathrm{s}$ associated with nodal metastasis. Oral Oncol 2011;47(2):108-113. DOI: 10.1016/j.oraloncology.2010.11.012.

54. Wang $H$, Liang $X$, Li M, et al. Chemokine (CC motif) ligand 18 upregulates Slug expression to promote stem-cell like features by activating the mammalian target of rapamycin pathway in oral squamous cell carcinoma. Cancer Sci 2017;108(8):1584-1593. DOI: 10.1111/cas.13289.

55. Lien MY, Tsai HC, Chang AC, et al. Chemokine CCL4 induces vascular endothelial growth factor $C$ expression and lymphangiogenesis by mir-195-3p in oral squamous cell carcinoma. Front Immunol 2018;9:412. DOI: 10.3389/fimmu.2018.00412.

56. Mao L, Zhuang R, Qin L, et al. CCL18 overexpression predicts a worse prognosis in oral squamous cell carcinoma (OSCC). Neoplasma 2020;67(3):700-706. DOI: 10.4149/neo_2020_190821N802.

57. Jiang X, Huang Z, Sun X, et al. CCL18-NIR1 promotes oral cancer cell growth and metastasis by activating the JAK2/STAT3 signaling pathway. BMC Cancer 2020;20(1):632. DOI: 10.1186/s12885-02007073-z. 